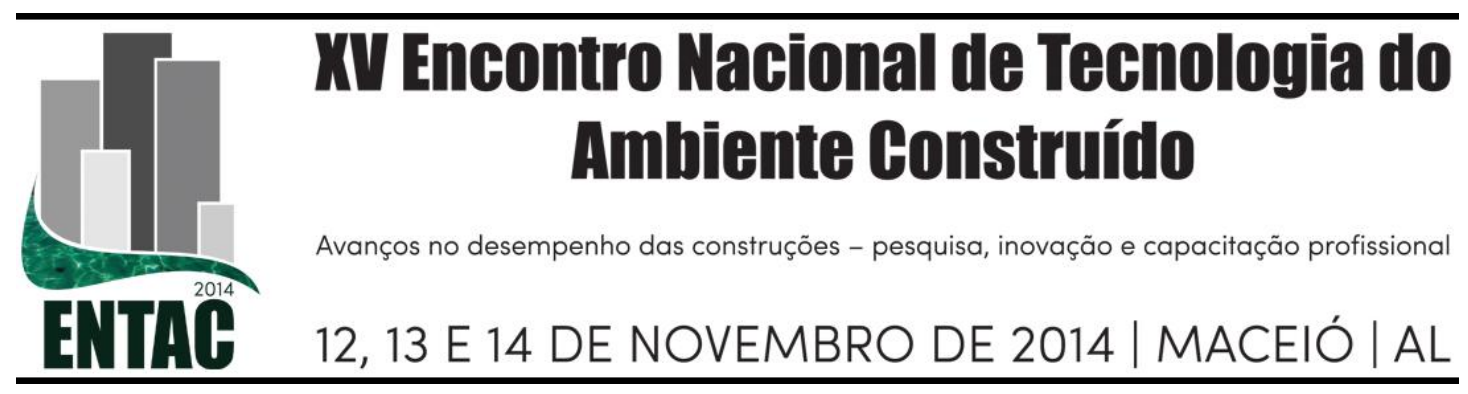

\title{
DIRETRIZES PARA A GESTÃO DE PROJETOS INDUSTRIAIS
}

\author{
Silva, Tássia; Melhado, Silvio
}

Mestre em Ciências, Escola Politécnica da Universidade de São Paulo, tsa29v@hotmail.com; Professor Associado, Escola Politécnica da Universidade de São Paulo, silvio.melhado@usp.br

\begin{abstract}
RESUMO
A crescente demanda por rapidez na construção, menores custos e maior controle da qualidade geram uma complexidade na gestão do processo de projeto. Estudos voltados aos projetos industriais ou obras por encomenda ainda são em minoria, ou seja, há poucos trabalhos desenvolvidos e publicados sobre este tema. Além disso, especificamente no segmento escolhido, a complexidade e a diversidade dos projetos, associadas às inúmeras exigências de mercado, demandam melhorias das práticas de gestão de projetos.

O trabalho tem como objetivo identificar, por meio de estudos de caso, as ações de gestão utilizadas em projetos industriais (obras por encomenda), caracterizar o processo de projeto, assim como analisar a atuação dos gestores de projeto e suas dificuldades.

A pesquisa em questão compõe-se de três fases que se sobrepõem: a primeira fase contempla uma revisão bibliográfica de conceitos relevantes para o estudo; a segunda corresponde à apresentação e discussão de estudos de caso, visando caracterizar a gestão do processo de projeto no segmento dos projetos industriais; a terceira e última fase corresponde à reflexão sobre os principais pontos críticos identificados nos estudos de caso. Como resultado, será possível propor diretrizes aos agentes envolvidos, visando à melhoria contínua e a potencializar o sucesso da gestão de projetos industriais.
\end{abstract}

Palavras-chave: gestão do processo de projeto, qualidade do projeto, projetos industriais.

\begin{abstract}
The diversity of the industrial projects and market requirements increasingly demand design process evolution. Research studies related to industrial projects are still quite rare, i.e. there is little work done and published on this theme. In the specific market branch, the rising need for speed in construction, lower costs and quality assurance generate complexity in managing the design process and require design quality improvement. Through a multiple case study, this paper aims to identify the design process, difficulties involved in the design manager tasks and the design management practices performed by the companies studied. The research was carried on throughout three stages: relevant literature review; case studies on industrial projects; and the reasoning based on the main points detected during the cases analysis.
\end{abstract}

Keywords: design management, design quality, industrial projects.

\section{INTRODUÇÃO}

Os empreendimentos industriais mobilizam diferentes especialidades na concepção e desenvolvimento de seus projetos. As particularidades determinam as atuações de cada agente envolvido. São eles: clientes, profissionais de projeto, consultores e construtores, cada qual com seus objetivos e perspectivas particulares. Segundo Grilo (2002), clientes demandam conformidade com o cronograma, orçamento e a qualidade especificada; projetistas buscam geração imediata e contínua de receita, reconhecimento profissional 
e emprego mínimo de recursos; construtores procuram meios e métodos viáveis, com um cronograma factível, um canteiro seguro e uma rentabilidade adequada.

As dificuldades técnicas e comerciais entre clientes e projetistas se iniciam logo nas contratações. Segundo Melhado et al. (2006), pode-se dizer que há poucos elementos reconhecidamente aceitos para a definição do conteúdo dos projetos a serem entregues e dos serviços a serem prestados pelos projetistas; é muito comum a falta de clareza por parte dos clientes de propósitos e objetivos a serem alcançados - faltam referências para escopo de serviços de projeto.

Este artigo em como objetivo identificar, por meio de estudos de caso, as etapas de gestão utilizadas em projetos industriais (obras por encomenda), caracterizar o processo de projeto, assim como analisar a atuação dos gestores de projeto e suas dificuldades.

Foi adotado o método de estudo de caso. De acordo com Yin (2001), estudos de caso podem ser considerados como uma das ferramentas possíveis para a realização de pesquisas. Esse tipo de ferramenta deve ser utilizado quando se pretende conhecer as características de eventos contemporâneos da vida real, principalmente quando o foco da pesquisa são as questões de "como" e "porque" determinados eventos ocorrem, sobre os quais o pesquisador possui pouco ou nenhum controle.

Como resultado, são propostas algumas diretrizes para a gestão de projetos industriais, com foco na qualidade do projeto, e visando à melhoria contínua e a potencializar o sucesso da gestão de projetos industriais.

\section{REVISÃO BIBLIOGRÁFICA}

\subsection{Gestão de projetos (project e design management)}

O processo de projeto constitui em ações e atividades inter-relacionadas que são realizadas de forma a obter um conjunto, definido por produtos, resultados ou serviços. A atuação conjunta dos grupos de processos é necessária em qualquer projeto, eles possuem "claras dependências internas e devem ser realizados na mesma sequência em cada projeto, independentemente da área de aplicação ou das especificações do ciclo de vida do projeto aplicado" (PMI, 2008).

De acordo com Coelho (2006), gestão de projetos é um ambiente integrador, e esta integração exige que cada processo seja associado e conectado a outros processos para facilitar a sua coordenação.

No início dos projetos, são os processos de iniciação que consomem a maioria dos recursos. Com o decorrer do tempo, os processos de planejamento, seguidos dos processos de execução e, finalmente, dos processos de encerramento, passam a consumir mais recursos.

Esse conjunto de processos pode se referir ao empreendimento como um todo (“project”), ao projeto (“design"), à execução da obra ou a todos esses. O que implica, neste último caso, uma sequência de fases de iniciação, planejamento, execução, controle e encerramento encadeadas.

\subsection{Aspectos críticos da gestão de projetos}

Etapas do Processo de Projeto: de acordo com Bertezini (2006), a subdivisão do processo de projeto em etapas é importante, pois permite: que sejam identificadas as atividades a serem realizadas durante o processo, visando atingir ao seu objetivo final; 
que cada atividade tenha seu conteúdo e informações necessárias bem definidas, além de seus produtos finais; que sejam atribuídas responsabilidades específicas para cada atividade, o que contribui para a transparência do processo e para o fluxo de informações; que sejam disponibilizados os recursos necessários para a execução de cada atividade, obtendo-se vantagens quanto a custos e prazos.

Agentes do Projeto: o desenvolvimento dos empreendimentos depende da interação entre os diversos agentes que atuam em cada etapa de seu ciclo de vida e que interferem direta ou indiretamente no processo de projeto (MEDEIROS, 2012). São constituídos por equipes multidisciplinares complexas, formadas por clientes, projetistas e construtores, com o objetivo de prover os recursos necessários a cada projeto. Os empreendimentos industriais mobilizam diferentes especialidades na concepção e desenvolvimento de seus projetos. A intensificação das exigências dos clientes em termos de prazos, custos e qualidade tem estimulado a introdução de inovações em tecnologias e métodos de gestão (GRILO, 2002). Neste cenário, o arranjo de uma equipe que privilegie a interatividade entre os agentes é de extrema relevância para que sejam atendidas essas limitações de custo, tempo e especificações do projeto exigidas.

Equipe Multidisciplinar e Coordenação: o aumento do volume de produtos gerados (disciplinas de projeto), a elevação do fluxo de informações e a necessidade de maior integração e compatibilização entre os intervenientes, em prazos de desenvolvimento global cada vez mais reduzidos, implicaram uma maior demanda e uma maior complexidade na gestão do processo de projeto (MELHADO et al., 2005). E pela multidisciplinaridade do processo, surge em decorrência a necessidade de criar uma orientação dos trabalhos de cada um dos especialistas, segundo um mesmo conjunto de diretrizes, com a priorização das tarefas de acordo com os objetivos gerais do empreendimento e baseada em critérios voltados à qualidade (MELHADO, 1994).

Estrutura Organizacional Matricial: as organizações matriciais, muito utilizadas por empresas projetistas, são uma combinação de características das organizações funcionais e projetizadas. As matrizes fracas mantêm muitas das características de uma organização funcional e o papel do gerente de projetos é mais parecido com a de um coordenador ou facilitador do que com o de um gerente de projetos propriamente dito. As matrizes fortes possuem muitas das características da organização projetizada e podem ter gerentes de projetos em tempo integral com autoridade considerável e pessoal administrativo trabalhando para o projeto em tempo integral. Enquanto a organização matricial balanceada reconhece a necessidade de um gerente de projetos, ela não fornece a ele autoridade total sobre o projeto (PMI, 2010).

Contratação: os sistemas contratuais exercem uma notável influência na gestão do empreendimento, na medida em que definem as relações contratuais e funcionais entre os agentes. Sistemas contratuais inadequados podem conduzir a acréscimos nos custos e atrasos, reivindicações e disputas, bem como perda da qualidade do investimento nos empreendimentos (GRILO; MELHADO, 2002). Para ser eficiente, a gestão de contratos requer planejamento, que deve ser feito antes da assinatura do contrato, em paralelo com a análise do risco de execução do projeto que se deseja contratar (RICARDINO; SILVA; ALENCAR, 2008).

Segundo Carvalho e Rabechini (2005), muitos empreendimentos requerem entregas que são impossíveis de serem desenvolvidas, pois dependem de competências que estão fora do âmbito do projeto. Nestes casos, os projetistas abrem mão de desenvolver produtos ou serviços no projeto e buscam, através de terceiros, mão de obra e bens para serem incorporados ao projeto. De acordo com Silva (1999), o processo de terceirização de 
atividades traz como consequência uma degradação de determinados processos de gerenciamento, pois muitas vezes é feita uma transferência da responsabilidade pela condução dos processos de planejamento, em um nível de detalhe incompatível com o grau de responsabilidade global transferida ao fornecedor, que pode implicar riscos nem sempre plenamente identificados.

Gestão da Informação e da Comunicação: as atividades relacionadas ao planejamento, execução, monitoramento e encerramento de um projeto são dependentes de informações que devem ser disponibilizadas no tempo da demanda (Fagundes et al., 2005). No início do projeto, quando da análise de requisitos, os agentes envolvidos são considerados como a principal fonte destes requisitos para o desenvolvimento do projeto. De acordo com o PMI (2008), os gerentes de projeto gastam a maior parte do seu tempo se comunicando com os membros da equipe e de outras partes interessadas do projeto, que sejam internas (em todos os níveis da organização) ou externas à organização. Conduzir e estimular a efetiva comunicação entre os agentes envolvidos no projeto têm se tornado tarefas difíceis. Oliveira (2005) afirma que a troca constante de fornecedores, as relações dinâmicas entre os agentes e seus diferentes interesses são fatores que tornam difícil a flexibilização do processo e tendem a incrementar também a dificuldade na troca de informações.

Gestão da Qualidade: com o aumento dos agentes envolvidos e maior complexidade de gestão, faz-se necessário a criação de mecanismos de avaliação, verificação e controle em cada etapa do projeto. Esta prática deve ser aplicada ao projeto como um todo, mesmo que parte dele seja elaborada por terceiros. Durante a execução do projeto, profissionais irão atender a esses requisitos considerando as melhores soluções técnicas e econômicas. A análise crítica é uma etapa fundamental do processo, pois é possível identificar e minimizar os desvios do projeto em relação aos requisitos inicialmente definidos (Melhado et. al., 2005).

Gestão do Conhecimento: o reflexo de uma estrutura organizacional aderente às estratégias da empresa é sua comunicação. Nas empresas inovadoras a comunicação não é transmitida de cima para baixo seguindo um só caminho e, normalmente, é compartilhada por um número significativo de interessados de forma a atenderem seus requisitos. Há pelo menos três variáveis a serem consideradas na gerência da inovação: informação, tempo e pessoas. As empresas que melhor gerenciam a inovação são aquelas que disponibilizam a informação certa para a pessoa certa na hora certa. Esta capacidade só é conseguida por meio de um processo de gerência do sistema de comunicação que no seu estágio de maior abrangência constitui-se no que é hoje chamado de gestão do conhecimento (RABECHINI JÚNIOR; CARVALHO; LAURINDO, 2002).

\section{ESTUDOS DE CASO}

\subsection{Empresa A}

A projetista é uma empresa brasileira de projetos, gerenciamento, engenharia e fornecimento de pacotes EPC/EPCM fundada em 1987. Possui matriz na cidade de São Paulo e filiais em: Vitória (ES), Belo Horizonte (MG), Salvador (BA), São Luís (MA), Belém (PA) e Neuquén, na Argentina. Além destas unidades, conta ainda com grupostarefa alocados no Brasil e no exterior.

Com cerca de 2.300 profissionais (sendo que $83 \%$ atuam na área técnica e $17 \%$ na administrativa), a projetista possui diversos clientes de diferentes segmentos como 
Mineração, Metalurgia, Siderurgia, Fertilizantes, Óleo e Gás, Petroquímica, Infraestrutura, Energia, Projetos Portuários, Gerenciamento de Implantação e Construções.

A empresa realiza serviços de consultoria e estudos (estudos de mercado / viabilidade técnico-econômica, impactos ambientais, HAZOP, análise de riscos de projetos); engenharia de projeto conceitual, básico e detalhado (disciplinas de Processos Químicos, Processos Mínero Metalúrgicos, Sistemas de Utilidades, Tubulações, Sistemas de Combate a Incêndio, Mecânica, Sistemas de Ventilação e Ar Condicionado, Eletricidade, Instrumentação, Controle e Automação, Arquitetura, Estruturas Metálicas, Estruturas de Concreto e Fundações, Infraestrutura Civil, Geologia e Geotecnia); Suprimentos (compras de equipamentos e materiais, diligenciamento de fabricação, inspeção de fabricação, coordenação e logística de transporte, gestão de materiais (controle de almoxarifado); Comissionamento /Assistência à Partida e Pré-Operação; Gerenciamento de Implantação e Construções.

A gestão de projetos na Empresa A está vinculada ao corpo gerencial da empresa formado pelos coordenadores de projeto e departamento de planejamento. Tanto os coordenadores quanto os planejadores respondem diretamente às diretorias dos segmentos industriais e de gerenciamento.

\subsection{Empresa B}

A empresa de Engenharia Consultiva foi fundada em 1990. Possui matriz em São Paulo e filiais no Rio de Janeiro/RJ e Esteio/RS, oferecendo serviços de Projetos Básicos e Detalhamento, Engenharia de Suprimentos, Gerenciamento de Empreendimentos, Serviços em EPC'M, Estudos Ambientais, Avaliações e Diagnósticos.

Com cerca de 800 colaboradores, a empresa atua nos segmentos industriais de Óleo, Gás e Petroquímica (Refinarias, Plantas Petroquímicas, Dutos e Terminais), incluindo Meio Ambiente e Recursos Hídricos (Saneamento de Água e Esgoto, Estudos Ambientais e Recursos Hídricos) e Infraestrutura (Transportes Multimodais, Infraestrutura Urbana e Energia).

A empresa possui uma ampla gama de disciplinas desenvolvidas por profissionais qualificados, são elas: analista de sistemas, coordenadores, gerentes, civil, elétrica, equipamentos, instrumentação, tubulação, processo químico, materiais, planejamento, qualidade e HSE, entre outras.

\subsection{Estudos de caso}

O Caso 1 refere-se a uma Usina Siderúrgica que terá capacidade anual de produção de 2,5 milhões de toneladas de placa. O empreendimento tem investimento estimado em $\mathrm{R} \$ 5,8$ bilhões e terá geração de 16 mil empregos na fase de implantação. Além da usina para produzir placas e aços laminados, o empreendimento compreende a construção de um acesso ferroviário, para receber o minério de ferro, e a construção de um terminal fluvial no rio Tocantins, para receber o carvão mineral e fazer o escoamento da produção siderúrgica até o Terminal Portuário de Vila do Conde, em Barcarena (PA). Além de atender à produção da siderúrgica, a futura hidrovia deverá servir a outras atividades socioeconômicas da região. Para elaboração dos projetos acima foram vendidas $5.000 \mathrm{Hh}$ (cinco mil horas técnicas) de engenharia e $1.000 \mathrm{Hh}$ (mil horas técnicas) de coordenação e planejamento, sendo prazo contratual de cinco meses, regime de contratação por preço global no valor total de $\mathrm{R} \$ 754.594,86$ para execução dos serviços. 
Quanto ao Caso 2, trata-se da implantação de uma Unidade de Recuperação de Hidrogênio e Construção Civil do Sistema de Enqriquecimento de Oxigênio - UHR. A unidade projetada terá uma capacidade nominal de carga de $322.000 \mathrm{Nm}^{3} / \mathrm{d}$ e produção estimada de $200.000 \mathrm{Nm}^{3} / \mathrm{d}$ de hidrogênio e $122.000 \mathrm{Nm}^{3} / \mathrm{d}$ de gás combustível. Para os serviços a Preço Global de Projeto de Detalhamento os honorários profissionais consistem em R $\$ 3.682 .712,80$ (três milhões seiscentos e oitenta e dois mil, setecentos doze reais e oitenta centavos) compreendendo 28 mil horas de engenharia e prazo previsto de 14 (meses).

Com relação ao Caso 3, tem por objetivo a elaboração de Projeto Básico e Executivo para novos estudos e/ou ampliações de edifícios, áreas de produção, envase, embalagem e utilidades existentes no site, a partir de projeto conceitual consolidado. A fábrica inclui um total de três unidades de produção para produtos cosméticos, fragrâncias e produtos de higiene pessoal. Para a prestação dos serviços definidos, o valor estimado do projeto é de $\mathrm{R} \$ 3.598 .182,78$ (três milhões quinhentos e noventa e oito mil, cento e oitenta e dois reais e setenta e oito centavos), com o prazo estimado de 5 meses e 27 mil horas de engenharia.

\subsection{Descrição e análise dos principais aspectos dos casos estudados}

Após coleta de dados baseada em um protocolo de estudo de caso múltiplo, confrontados com a bibliografia, foram estabelecidos temas prioritários de análise, subdivididos em subtemas (conforme se pode ver nas duas primeiras colunas do Quadro 1). O Quadro 1 apresenta, de forma resumida, uma síntese contendo as principais observações realizadas nos três estudos de caso.

\section{Quadro 1 - Síntese dos Estudos de Caso}

\begin{tabular}{|c|c|c|c|c|}
\hline Tema & Subtema & Caso 1 (Empresa A) & Caso 2 (Empresa B) & Caso 3 (Empresa A) \\
\hline $\begin{array}{l}\text { Gestão de } \\
\text { Projetos }\end{array}$ & $\begin{array}{l}\text { Project } \\
\text { Mana- } \\
\text { gement }\end{array}$ & $\begin{array}{l}\text { Iniciação: informação de } \\
\text { referência (falta de } \\
\text { informações reais e } \\
\text { confiáveis dos principais } \\
\text { equipamentos do } \\
\text { empreendimento / } \\
\text { sondagem realizada em } \\
\text { período de seca) } \\
\text { Planejamento: } \\
\text { contratação de terceiros } \\
\text { Execução: integração } \\
\text { entre atividades, riscos } \\
\text { Controle: terceiros } \\
\text { Encerramento: n.a. }\end{array}$ & $\begin{array}{l}\text { Iniciação: informação de } \\
\text { referência ("as built" } \\
\text { desatualizado - } \\
\text { instalações não } \\
\text { mapeadas / } \\
\text { especificações e } \\
\text { quantidades de } \\
\text { materiais falhas) } \\
\text { Planejamento: mudança } \\
\text { de escopo / questões } \\
\text { climáticas / } \\
\text { reestruturação } \\
\text { organizacional da } \\
\text { projetista } \\
\text { Execução: integração de } \\
\text { equipe projeto-obra } \\
\text { (fator geográfico } \\
\text { dificultou o processo de } \\
\text { comunicação) }\end{array}$ & $\begin{array}{l}\text { Iniciação: informação de } \\
\text { referência (falta de } \\
\text { informações reais e } \\
\text { confiáveis dos principais } \\
\text { equipamentos - } \\
\text { utilizados catálogos / lay } \\
\text { out da área de } \\
\text { microbiologia divergia de } \\
\text { informações enviadas no } \\
\text { início do projeto / atraso } \\
\text { na definição de reatores } \\
\text { / Problemas na fase de } \\
\text { execução - "as built" - } \\
\text { interferências de } \\
\text { tubulações) } \\
\text { Falta de experiência da } \\
\text { projetista em BIM }\end{array}$ \\
\hline
\end{tabular}




\begin{tabular}{|c|c|c|c|c|}
\hline & & & \begin{tabular}{|l} 
Controle: Gestão de MO \\
(falta de controle das \\
modificações realizadas - \\
falta de registro das \\
premissas adotadas) \\
Encerramento: n.a.
\end{tabular} & $\begin{array}{l}\text { Planejamento: } \\
\text { esclarecimento do nível } \\
\text { de detalhamento do } \\
\text { projeto / rotatividade da } \\
\text { equipe da projetista / } \\
\text { inexperiência em BIM e } \\
\text { sistema hidrossanitário a } \\
\text { vácuo (contratação de } \\
\text { terceiros) } \\
\text { Execução: falta de } \\
\text { conhecimento de BIM; } \\
\text { Controle: Atividades de } \\
\text { modelagem 3D ( a } \\
\text { inexperiência dificultou } \\
\text { controle de atividades / } \\
\text { Muitas alterações de } \\
\text { escopo - dificuldade na } \\
\text { gestão de MO } \\
\text { Encerramento: n.a. }\end{array}$ \\
\hline & $\begin{array}{l}\text { Design } \\
\text { Mana- } \\
\text { gement }\end{array}$ & \begin{tabular}{|l|} 
Análise crítica e \\
verificação do projeto \\
(design)
\end{tabular} & $\begin{array}{l}\text { Análise crítica e } \\
\text { verificação do projeto } \\
\text { (design) }\end{array}$ & $\begin{array}{l}\text { Falta de know how (BIM } \\
\text { e sistema } \\
\text { hidrossanitário) }\end{array}$ \\
\hline \multirow{3}{*}{$\begin{array}{l}\text { Gestão } \\
\text { do } \\
\text { Processo } \\
\text { de } \\
\text { Projeto }\end{array}$} & $\begin{array}{l}\text { Etapas } \\
\text { do } \\
\text { Processo } \\
\text { de } \\
\text { Projeto }\end{array}$ & $\begin{array}{l}\text { Falta de informações } \\
\text { necessárias para } \\
\text { desenvolvimento das } \\
\text { atividades - utilizado } \\
\text { referências disponíveis } \\
\text { em etapas anteriores } \\
\text { (projeto básico); } \\
\text { Falta de recursos } \\
\text { disponíveis para } \\
\text { realização do projeto de } \\
\text { drenagem - contratação } \\
\text { de terceiros; } \\
\text { Falta de gestão da } \\
\text { contratação de terceiros. }\end{array}$ & $\begin{array}{l}\text { Falta de informações } \\
\text { para execução da obra } \\
\text { (“as built”) } \\
\text { Gestão de Risco para } \\
\text { atividades que } \\
\text { dependiam de fatores } \\
\text { externos } \\
\text { (desmobilização de } \\
\text { canteiro do vizinho) } \\
\text { Gestão de Risco para } \\
\text { questão climática? } \\
\text { Precisão (verificação) do } \\
\text { projeto quanto a } \\
\text { quantificação de } \\
\text { materiais }\end{array}$ & $\begin{array}{l}\text { Atraso na definição de } \\
\text { requisitos (dados de } \\
\text { processo, especificações } \\
\text { de tanques..) } \\
\text { Falta de informações de } \\
\text { referência necessárias } \\
\text { para desenvolvimento } \\
\text { das atividades - utilizado } \\
\text { referências disponíveis } \\
\text { em catálogos de } \\
\text { equipamentos } \\
\text { Grande quantidade e } \\
\text { nível de alterações de } \\
\text { projeto solicitado pelo } \\
\text { cliente. }\end{array}$ \\
\hline & $\begin{array}{l}\text { Agentes } \\
\text { Envol- } \\
\text { vidos }\end{array}$ & $\begin{array}{l}\text { Cliente; } \\
\text { Consultoria técnica } \\
\text { externa; } \\
\text { Projetista }\end{array}$ & $\begin{array}{l}\text { Cliente; } \\
\text { Construtora/ } \\
\text { Gerenciadora; } \\
\text { Projetista; } \\
\text { Montadora }\end{array}$ & $\begin{array}{l}\text { Cliente; } \\
\text { Construtora / } \\
\text { Montadora; } \\
\text { Projetista }\end{array}$ \\
\hline & $\begin{array}{l}\text { Equipe } \\
\text { Multidis- } \\
\text { ciplinar e } \\
\text { Coorde- } \\
\text { nação }\end{array}$ & \begin{tabular}{|l} 
Rotatividade de \\
coordenadores e \\
planejadores
\end{tabular} & $\begin{array}{l}\text { Rotatividade dos } \\
\text { membros da equipe de } \\
\text { projeto (coordenadores, } \\
\text { job leaders e projetistas) } \\
\text { devido à carência de } \\
\text { profissionais e também } \\
\text { ao atendimento a outros } \\
\text { projetos gerou perda de } \\
\text { histórico do projeto, } \\
\text { revisões de projetos já } \\
\text { aprovados e muito } \\
\text { retrabalho }\end{array}$ & $\begin{array}{l}\text { Muitas alterações na } \\
\text { liderança, tanto no corpo } \\
\text { técnico como na gestão } \\
\text { por parte da projetista }\end{array}$ \\
\hline
\end{tabular}




\begin{tabular}{|c|c|c|c|c|}
\hline $\begin{array}{l}\text { Contrata- } \\
\text { ção de } \\
\text { Projetos }\end{array}$ & $\begin{array}{l}\text { Modali- } \\
\text { dade }\end{array}$ & Preço Global & Preço Global & Preço Global \\
\hline $\begin{array}{c}\text { Estrutura } \\
\text { Organiza- } \\
\text { cional }\end{array}$ & Tipologia & Matricial & Matricial & Matricial \\
\hline \multirow[b]{2}{*}{$\begin{array}{l}\text { Gestão da } \\
\text { Infor- } \\
\text { mação e } \\
\text { da } \\
\text { Comuni- } \\
\text { cação }\end{array}$} & $\begin{array}{c}\text { Gestão } \\
\text { da Infor- } \\
\text { mação }\end{array}$ & $\begin{array}{l}\text { Informações de } \\
\text { referência faltantes } \\
\text { Informações de projeto } \\
\text { recebidas por terceiros } \\
\text { não verificadas, ou seja, } \\
\text { não confiáveis }\end{array}$ & $\begin{array}{l}\text { Atraso na entrega do } \\
\text { projeto (recursos } \\
\text { insuficientes para a } \\
\text { necessidade do projeto) } \\
\text { gerando problemas a } \\
\text { resolver na fase de } \\
\text { execução } \\
\text { Falta de informação pelo } \\
\text { cliente para "as built" }\end{array}$ & $\begin{array}{l}\text { Informações de } \\
\text { referência faltantes }\end{array}$ \\
\hline & $\begin{array}{l}\text { Gestão } \\
\text { da } \\
\text { Comu- } \\
\text { nicação }\end{array}$ & $\begin{array}{l}\text { Falta de plano de } \\
\text { comunicação com } \\
\text { terceiro }\end{array}$ & $\begin{array}{l}\text { Não cumprimento da } \\
\text { matriz de distribuição de } \\
\text { documentos (falta de } \\
\text { controle de versões dos } \\
\text { projetos / utilização de } \\
\text { revisões superadas) } \\
\text { Fator geográfico equipe } \\
\text { projeto - equipe obra } \\
\text { Falta de equipe de } \\
\text { engenharia } \\
\text { multidisciplinar para } \\
\text { verificação e análise } \\
\text { crítica do projeto } \\
\text { A projetista não } \\
\text { mobilizou equipe para } \\
\text { assistência técnica a } \\
\text { obra devido à redução } \\
\text { de orçamento, ou seja, } \\
\text { não foram alocados } \\
\text { recursos para essa } \\
\text { atividade } \\
\text { Falta de participação de } \\
\text { agentes envolvidos em } \\
\text { reuniões e decisões }\end{array}$ & $\begin{array}{l}\text { As várias formas de } \\
\text { recebimento de projetos } \\
\text { (solicitadas pelo próprio } \\
\text { cliente) gerou utilização } \\
\text { de revisões superadas na } \\
\text { obra } \\
\text { O cliente também não } \\
\text { tinha controle interno de } \\
\text { recebimento de projetos } \\
\text { efetivo } \\
\text { Falta de recursos por } \\
\text { parte do cliente para } \\
\text { atender a demanda de } \\
\text { definições de projeto } \\
\text { (equipe reduzida sem } \\
\text { todas as especialidades } \\
\text { necessárias) }\end{array}$ \\
\hline $\begin{array}{l}\text { Gestão da } \\
\text { Quali- } \\
\text { dade }\end{array}$ & & $\begin{array}{l}\text { Falta de qualidade nas } \\
\text { informações de } \\
\text { referência recebidas } \\
\text { pelo cliente } \\
\text { Falta de verificação e } \\
\text { análise crítica dos } \\
\text { projetos quanto às } \\
\text { contratações externas }\end{array}$ & $\begin{array}{l}\text { Validação de projeto } \\
\text { pelo cliente quanto a } \\
\text { análise, comentário e } \\
\text { aprovação (não havia } \\
\text { recurso) } \\
\text { Utilização de revisões } \\
\text { superadas de projeto na } \\
\text { obra } \\
\text { Informação de } \\
\text { referência pelo cliente } \\
\text { ("as built”) }\end{array}$ & $\begin{array}{l}\text { Informação de } \\
\text { referência pelo cliente } \\
\text { (no "as built" não havia } \\
\text { locação de dutos, o que } \\
\text { causou acidente em obra } \\
\text { quando da perfuração de } \\
\text { estacas) }\end{array}$ \\
\hline
\end{tabular}




\begin{tabular}{|c|l|l|l|l|}
\hline $\begin{array}{c}\text { Gestão } \\
\text { do }\end{array}$ & $\begin{array}{l}\text { Falta de controle e } \\
\text { banco de dados de } \\
\text { Conhe- } \\
\text { cimento }\end{array}$ & $\begin{array}{l}\text { Organização das } \\
\text { aprendida quanto à } \\
\text { informações (banco de } \\
\text { dados do projeto) }\end{array}$ & $\begin{array}{l}\text { Falta de controle e } \\
\text { banco de dados de } \\
\text { conhecimento: lição } \\
\text { aprendida quanto ao uso } \\
\text { de BIM }\end{array}$ \\
\hline
\end{tabular}

n.a. - não avaliado

Fonte: Pesquisa de Mestrado em andamento - Primeira Autora

\section{DIRETRIZES}

Como resultado da análise dos casos e diante dos conceitos de gestão apontados pela revisão bibliográfica, foram detectados pontos em comum que sugerem algumas diretrizes preliminares.

Os dados iniciais para o desenvolvimento do projeto (coleta / entrada de informações) têm grande relevância e estas informações devem ser confiáveis, para que o projeto tenha qualidade, diminuindo riscos em relação a atrasos e aumento de custos. No Caso 1, foi possível observar que as informações que alimentaram o processo de projeto possuíam um grau de incerteza muito grande e, com a falta de colaboração do cliente no que diz respeito à qualidade da informação, tornaram-se uma grande fonte de prejuízos. No Caso 3, faltaram informações de referência. Nesse mesmo caso, foi bastante crítico o desconhecimento e inexperiência da Empresa Projetista para o uso da Modelagem da Informação da Construção (BIM). Também foi constatada deficiência por alocação insuficiente de recursos (Caso 2). Em entregas parciais dos projetos, a integração entre as disciplinas envolvidas, compatibilização e análise crítica devem ser considerados "pilares" do processo de projeto. Foram observadas deficiências graves de gestão nesse aspecto, nos casos estudados. Outro aspecto crítico diz respeito à gestão da qualidade. No Caso 2, problemas gerados pela falta de controle na distribuição de documentos levaram à utilização de versões canceladas pela equipe de obra.

Em um exercício rápido, podem ser elencadas cinco diretrizes para a gestão de projetos, dentro do contexto característico dos três casos:

Diretriz 1: prioridade deve ser dada à definição e correta aplicação da matriz de responsabilidades do projeto, incluindo-se a o cliente e suas equipes técnicas, como forma de prevenir decisões erradas, mal fundamentadas ou não validadas.

Diretriz 2: atenção quanto à qualidade da informação disponibilizada pelo cliente ou por terceiros, submetendo-a a verificação e análise crítica, em todas as etapas, de modo a tornar o projeto confiável e reduzir retrabalho.

Diretriz 3: um sistema de controle de documentação, confiável e capaz de rastrear a circulação dos documentos de projeto, é imprescindível para se garantir que as informações corretas prevaleçam.

Diretriz 4: a qualificação e dimensionamento das equipes de projeto deve ter garantia de adequação aos requisitos de projeto estabelecidos desde o contrato; eventuais situações de qualificação insuficiente devem ser objeto de análise e mitigação de riscos.

Diretriz 5: identificada a necessidade de aquisição de serviços externos, deve-se elaborar uma análise de riscos, principalmente em relação a prazo e qualidade, de modo a garantir que o trabalho de uma equipe terceirizada atenda aos objetivos do cliente.

\section{CONSIDERAÇÕES FINAIS}

Um dilema sugerido pela análise dos estudos de caso está intimamente ligado às 
responsabilidades atribuídas a partir da ocorrência de problemas. Houve quebras de procedimento, em alguns casos, mas parece ter faltado uma gestão mais efetiva em várias situações; especialmente, com enfoque preventivo.

No entanto, a maioria dos desvios no processo de projeto identificados nos projetos industriais estudados possui a participação da coordenação de projetos como a responsável pelo resultado obtido. Dificuldades e falhas da coordenação, comuns aos casos analisados, significaram prejuízos quanto ao prazo, custo e qualidade comprometendo o sucesso do projeto.

Outra questão de difícil equacionamento para a gestão de projetos no segmento estudado consiste em como controlar o "risco-cliente"; em boa parte das dificuldades e insucessos relatados, o cliente estava na origem do processo, revelando-se um fator de risco que não teve adequado tratamento por parte dos gestores.

\section{REFERÊNCIAS}

BERTEZINI, A.L., Métodos de avaliação do processo de projeto de arquitetura na construção de edifícios sob a ótica da gestão da qualidade - Dissertação, Escola Politécnica da USP, São Paulo, 2006.

COELHO, M.C.P. Metodologia de gestão de projetos de edificações baseadas no PMBoK do PMI. Monografia de MBA apresentada à Escola Politécnica da USP, São Paulo, 2006.

GRILO, L.M. Gestão do processo de projeto no segmento de construção de edifícios por encomenda. Tese (Doutorado) - Escola Politécnica da USP, São Paulo, 2002.

GRILO, L.M.; MELHADO, S.B., Novas formas de contratação e organização dos empreendimentos no segmento de construção de edifícios para terceiros, Encontro Nacional de Tecnologia do Ambiente Construído. IX ENTAC, Foz do Iguaçu, 2002.

MEDEIROS, M.C.I., Gestão do conhecimento aplicada ao processo de projeto na construção civil: estudo de caso em construtoras. Dissertação (Mestrado) - Escola Politécnica da USP, São Paulo, 2012.

MELHADO, S.B. Qualidade do projeto na construção de edifícios: aplicação ao caso das empresas de incorporação e construção. São Paulo: 1994. 294p. Tese (Doutorado) - Escola Politécnica da USP.

MELHADO, S.B. et al. Coordenação de projetos de edificações, São Paulo, 2005.

MELHADO, S.B. et al. A gestão de projetos de edificações e o escopo de serviços para coordenação de projetos. Sâo Paulo, 2006.

OLIVEIRA, O.J., Modelo de gestão para pequenas empresas de projetos de edifícios. São Paulo: 2005. Tese (Doutorado) - Escola Politécnica da USP.

PMI - PROJECT MANAGEMENT INSTITUTE. PMBoK: Um guia do conhecimento em gerenciamento de projetos, $4^{\mathrm{a}}$ edição, 2008.

RABECHINI Junior, R,; CARVALHO, M.M.; LAURINDO, F.J.B., Fatores críticos para implementação de gerenciamento por projetos: o caso de uma organização de pesquisa. Produção, V.12 N.2, 2002.

RICARDINO, R.; SILVA, S.A.R.; ALENCAR, C.T., Administração de contrato em projetos de construção pesada no Brasil: um estudo da interface com o processo de análise do risco. Boletim Técnico da Escola Politécnica da USP, São Paulo, 2008.

SILVA, S.A.R., Programações por recurso: o desenvolvimento de um método de nivelamento e alocação com números nebulosos para o setor da construção civil. São Paulo: 1999. Tese (Doutorado) - Escola Politécnica da USP.

YIN, R.K. Estudo de caso - planejamento e métodos, Bookman, 2001. 